\title{
Variations in salinity tolerance of malaria vectors of the Anopheles subpictus complex in Sri Lanka and the implications for malaria transmission
}

\author{
Sinnathamby N Surendran ${ }^{1 *}$, Pavillupillai J Jude ${ }^{1}$ and Ranjan Ramasamy ${ }^{2 *}$
}

\begin{abstract}
Background: Anopheles subpictus sensu lato, a widespread vector of malaria in Asia, is reportedly composed of four sibling species A-D based on distinct cytogenetic and morphological characteristics. However An. subpictus species B specimens in Sri Lanka are termed An. subpictus B/ An. sundaicus because of recent genetic data. Differences in salinity tolerance and coastal/inland prevalence of An. subpictus sibling species that were not previously established in Sri Lanka are presented here.

Results: Specimens with morphological characteristics of all four Indian An. subpictus sibling species were found in Sri Lanka. Sibling species A, C and D tended to be predominant in inland, and An. subpictus species B/An. sundaicus, in coastal localities. Sibling species $C$ was predominant in both adult and larval inland collections. Larvae of An. subpictus B/An. sundaicus were found in inland and coastal sites, including a lagoon, with salinity varying from 0 to 30 ppt. An. subpictus sibling species A, C and D larvae were present in water of salinity between 0 to 4 ppt. An. subpictus C, D and An. subpictus B/An. sundaicus larvae showed compatible differential salinity tolerance in laboratory tests. The first instar larvae of An. subpictus B/An. sundaicus showed $100 \%$ survival up to $15 \mathrm{ppt}$ in comparison to species $C$ and $D$ where the corresponding values were 3 ppt and 6 ppt respectively. However all third instar larvae of An. subpictus B/An. sundaicus survived up to 30 ppt salinity whereas An. subpictus C and D tolerated up to 4 ppt and 8 ppt salinity respectively.

Conclusions: The results suggest that An. subpictus species B/An. sundaicus breed in fresh, brackish and nearly saline water while An. subpictus species $C$ and D do so in fresh and less brackish waters in Sri Lanka, as in India. Because of the established role of An. sundaicus s.l. and An. subpictus s.l. as malaria vectors, the findings indicate a need for greater monitoring of brackish water breeding habitats in Asia. Tolerance to 15 ppt salinity may also constitute a simple method for differentiating An. subpictus B/An. sundaicus larvae from those of An. subpictus species $C$ and $D$ in field studies.
\end{abstract}

\section{Background}

The major vector of Plasmodium falciparum and Plasmodium vivax malaria in Sri Lanka [1,2] is Anopheles culicifacies species E, but Anopheles subpictus s.l is also a malaria vector in many parts of the island [3-5] and elsewhere in Asia [6-8]. An. subpictus s.l. can additionally transmit filarial parasites and Japanese encephalitis and

\footnotetext{
* Correspondence: noble@jfn.ac.lk; ranjan.ramasamy@ubd.edu.bn

'Department of Zoology, Faculty of Science, University of Jaffna, Jaffna, Sri Lanka

${ }^{2}$ Institute of Health Sciences, Universiti Brunei Darussalam, Gadong, Brunei Darussalam

Full list of author information is available at the end of the article
}

West Nile viruses $[6,9,10]$. The taxon An. subpictus is reported to be a complex of four sibling species, viz. A, B, $C$ and $D$ in India [6,7], that are differentiated through characteristic paracentric fixed inversions on the X-chromosome and stage-specific morphometric characteristics e.g. the number of ridges in egg floats, larval mesothoracic seta 4, pupal setae and ornamentation of the palpi of adult females [7]. Previous studies have reported the presence of all four sibling species in Sri Lanka based on the morphological characteristics observed in India $[11,12]$.

Existing evidence suggests that members of the Subpictus Complex are able to breed in inland and coastal habitats, that they are generally zoophagic, both exophilic and

\section{Ciomed Central}


endophilic, and that they are able to tolerate a range of salinities in their breeding sites [1,6,12-14]. The limited data on bio-ecological differences between members of the An. subpictus complex in Sri Lanka and elsewhere in Asia and their geographical distribution have been recently reviewed $[1,6,13]$. They indicate a need for more detailed studies to establish differences between sibling species that contribute to the range of bio-ecological characteristics observed in the Subpictus Complex.

$A n$. subpictus species B is generally found in coastal areas of India and is reported to show greater salinity tolerance when compared to species A, C and D in breeding sites in India [14] and elsewhere in Asia [13]. Many An. subpictus species B specimens from Eastern Sri Lanka, and some others from Southeast Asia, although morphologically similar to An. subpictus, are genetically closer to Anopheles sundaicus [15]. Therefore mosquitoes in Sri Lanka with morphological characters of Indian An. subpictus B are termed An. subpictus B/ $A n$. sundaicus in this article. The differential salinity tolerance and preferences for coastal or inland breeding sites of individual members of the Subpictus Complex are yet to be clearly established in Sri Lanka. Characterization of differences in their larval habitats is important as there are known genetic differences between corresponding anophelines in Sri Lanka and neighbouring India e.g. An. culicifacies species B and E [16].

Differences in bio-ecological traits of sibling species of malaria vectors are essential for adopting appropriate vector control measures. Characteristics of malaria transmission in coastal areas in the North Central Province [12] and inland areas of North Central and Eastern Provinces [3-5] of Sri Lanka indicate the involvement of An. subpictus sibling species B and species $\mathrm{C} / \mathrm{D} / \mathrm{A}$ in the respective areas. Larval control measures have hitherto been almost exclusively applied to fresh water breeding sites of malaria vectors in Sri Lanka. The salinity tolerance and prevalence in coastal and inland sites of mosquitoes identified morphologically as belonging to the An. subpictus complex in sites located in the Eastern and Northwestern provinces of Sri Lanka were therefore investigated and the results reported here.

\section{Results}

Field collections of blood-fed adult An. subpictus females of different sibling species

Blood-fed An. subpictus-like females could be collected from sites in all the four Sri Lankan districts studied [Figure 1]. Of the 4098 blood-fed adult females that were collected during the study, 1247 laid eggs. Microscopic determination of the numbers of ridges in egg floats laid by them suggested the presence of An. subpictus B/ An. sundaicus and $A n$. subpictus species A, C and D [Table 1]. While sibling species A, C and D tended to predominate in inland localities (localities located $\geq 2.5 \mathrm{~km}$ from the coast), species $\mathrm{B} / \mathrm{An}$. sundaicus tended to be more prevalent in coastal areas. Among the inland species, sibling species $\mathrm{C}$ was predominant in both adult and larval collections [Tables 1 and 2]. There were fewer An. subpictus A-like females compared to other sibling species in the collections.

\section{Characteristics of larval breeding habitats of An. subpictus sibling species}

In parallel studies, 1930 larvae could be classified by examination of seta $4 \mathrm{M}$ and the results showed that larvae with characteristics of all four An. subpictus sibling species were present in both inland and coastal locations [Table 2]. However there was a tendency for larvae with characteristics of An. subpictus $\mathrm{B} / \mathrm{An}$. sundaicus to predominate in coastal localities [Table 2]. Larvae with characteristics of $A n$. subpictus $\mathrm{B} / A n$. sundaicus were collected from both inland and coastal locations with salinity levels varying from 0 to $30 \mathrm{ppt}$ (fresh, brackish and saline water are defined as having $<0.5,0.5$ to 30 and $>30$ ppt salt respectively). Furthermore they were the only larvae collected from sites where the salinity was $>4$ ppt. Larvae with characteristics of An. subpictus A, C and $\mathrm{D}$ were only collected from sites where the salinity was $\leq 4$ ppt. Collection of large numbers of An. subpictus A, C and D larvae in coastal areas was associated with the rainy season (October to January) during which the salinity levels of the water bodies decreased due to dilution by rain water [Table 2]. All the breeding sites, except that in Muthur, were exposed to direct sunlight. All sites, except those in Palaiyutru and Thonikkal, had vegetation such as rooted and un-rooted floating plants (e.g. Hydrilla spp, Nelimbium spp, Salvinea spp and Eichornia spp) and green algae. An. subpictus B/An. sundaicus larvae were also collected $\sim 15 \mathrm{~m}$ from land in the shallow waters of a lagoon at Kallady where the salinity was 30 ppt. The larvae at this site were found associated with marine algae and plants and exposed to direct sunlight [Figure 2]. The $\mathrm{pH}$ and dissolved oxygen concentrations of the breeding sites where the larvae were collected varied from 7.1 to 8.4 and 1.1 to $2.6 \mathrm{mg} / \mathrm{L}$ respectively.

\section{Laboratory investigations on salinity tolerance of larvae}

Larvae from mosquitoes with characteristics of $A n$. subpictus $\mathrm{B} / A n$. sundaicus, and An. subpictus $\mathrm{C}$ and $\mathrm{D}$ differed in their ability to tolerate salinity. All first instar larvae with characteristics of An. subpictus $\mathrm{B} / A n$. sundaicus survived in water with up to $15 \mathrm{ppt}$ salinity [Figure 3]. In contrast, $100 \%$ survival of larvae of An. subpictus C and D were only obtained at up to 3 ppt and 6 ppt salinity respectively. Also the third instar larvae of An. subpictus $\mathrm{B} / \mathrm{An}$. sundaicus recorded $100 \%$ survival at up to $30 \mathrm{ppt}$ salinity whereas those classified as An. subpictus C and D 


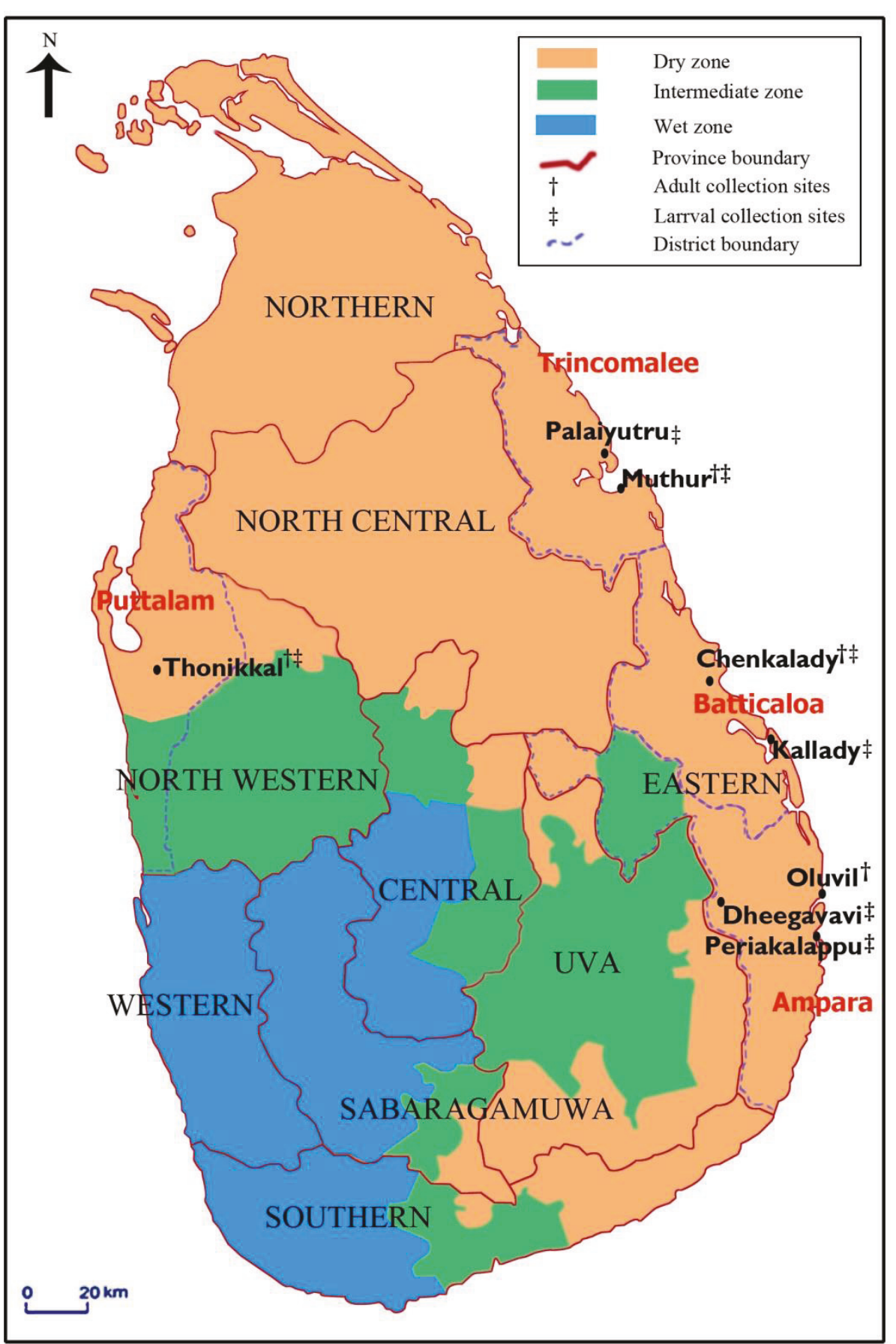

Figure 1 Map showing the adult and larval collection sites and the climatic zones (dry, intermediate and wet) of Sri Lanka.

showed $100 \%$ survival at only up to 4 ppt and 8 ppt salinity respectively [Figure 4].

\section{Discussion}

Some members of the different anopheline species complexes show high salinity tolerance and are associated with coastal malaria transmission. Anopheles melas and
Anopheles merus within the Anopheles gambiae complex are examples from Africa [17]. Anopheles farauti s.s. and Anopheles irenicus (formerly designated An. farauti No. 7 ) in the Farauti Complex are reported to be salinity-tolerant in Australasia [13,18]. Malaria vectors of the An. sundaicus complex in Southeast Asia are well known brackish water breeders that are also able to 
Table 1 Adult females in field collections characterized as An.subpictus sibling species A, B/An. sundaicus, C and D through morphology of laid eggs

\begin{tabular}{ccccccc}
\hline Districts & Location & $\begin{array}{c}\text { Type of } \\
\text { locality }\end{array}$ & \multicolumn{5}{l}{ Numbers of adult females } \\
\cline { 3 - 7 } & & A & $\begin{array}{c}\text { B/An. } \\
\text { sundaicus }\end{array}$ & C & D \\
\hline Batticaloa & Chenkalady & Inland & 4 & 187 & 387 & 82 \\
Ampara & Oluvil & Coastal & 0 & 65 & 67 & 20 \\
Puttalam & Thonikkal & Inland & 0 & 74 & 120 & 34 \\
Trincomalee & Muthur & Coastal & 0 & 24 & 0 & 0 \\
& & Inland & 0 & 33 & 128 & 22 \\
\hline TOTAL & & $\mathbf{4}$ & $\mathbf{3 8 3}$ & $\mathbf{7 0 2}$ & $\mathbf{1 5 8}$ \\
\hline
\end{tabular}

breed in freshwater [13]. An. sundaicus larvae (cytotype D) on the Car Nicorbar Island were collected from breeding sites with salinity ranging from 0 to $14 \mathrm{ppt}$ [19]. In Indonesia, An. sundaicus s.l and An. subpictus s. $l$ populations cohabit in the same breeding sites with salinity ranging from 5 to 10 ppt [20]. An. subpictus B/ $A n$. sundaicus were collected previously from stagnant brackish water bodies in Kallady and Oluvil in Eastern Sri Lanka [15]. The present findings show that An. subpictus $\mathrm{B} / \mathrm{An}$. sundaicus populations are present in breeding sites containing algae and exposed to sunlight with 0 to 30 ppt salinity in Sri Lanka. An. sundaicus s.l. and An. subpictus s.l. have also been reported by others to prefer breeding in sunlit sites that contain algae [20]. The $\mathrm{pH}$ and dissolved oxygen concentrations observed here fall within the ranges reported for An. subpictus s.l. and An. sundaicus s.l. larval breeding habitats elsewhere $[19,20]$.

The collection of adult female mosquitoes and larvae of the different sibling species of the Subpictus Complex showed an association in inland and coastal areas. Sibling species $\mathrm{A}, \mathrm{C}$ and $\mathrm{D}$ were generally predominant in inland localities even though their larvae were found to tolerate salinity levels up to $4 \mathrm{ppt}$ in breeding sites. On the other hand, An. subpictus $\mathrm{B} / A n$. sundaicus tended to be more prevalent in coastal localities but their larvae were found to tolerate wide range of salinity levels ( 0 to 30 ppt). This shows that Sri Lankan An. subpictus B/An. sundaicus are similar to malaria vectors of the Sundaicus Complex in being able to tolerate a range of salinities and breed in fresh and brackish waters.

This is the first study to evaluate the salinity tolerance of the An. subpictus-like mosquitoes under both field and laboratory conditions. The greater salinity tolerance of An. subpictus $\mathrm{B} / A n$. sundaicus compared to An. subpictus $\mathrm{C}$ and $\mathrm{D}$ larvae observed in laboratory studies is consistent with their presence in more brackish water in nature. The coastal populations of the Subpictus Complex have been particularly incriminated as malaria vectors in India $[21,22]$ and the Puttalam district in western Sri Lanka [11]. The ability of An. subpictus B/An. sundaicus to breed in brackish (0.5-30 ppt salt) and fresh water $(<0.5 \mathrm{ppt}$ salt $)$ indicates that it is versatile enough to transmit malaria in large parts of Sri Lanka, which is a relatively small island with an extensive coastline and large tracts of brackish water bodies that extend deep

Table 2 Larvae with characteristics of An.subpictus sibling species A, B/An. sundaicus, C and D collected from different sites during the period February 2009 - June 2010

\begin{tabular}{|c|c|c|c|c|c|c|c|c|}
\hline \multirow[t]{2}{*}{ District } & \multirow[t]{2}{*}{ Location } & \multirow[t]{2}{*}{ Type of locality } & \multirow[t]{2}{*}{ Type of breeding site } & \multirow[t]{2}{*}{ Salinity (ppt) } & \multicolumn{4}{|c|}{$\begin{array}{l}\text { Number of larvae of the } \\
\text { An. subpictus sibling species }\end{array}$} \\
\hline & & & & & $A$ & B & C & D \\
\hline \multirow[t]{8}{*}{ Batticaloa } & Chenkalady & Inland & Pond & 0 & - & 06 & 26 & 09 \\
\hline & Kallady & Coastal & Sand pool & 0 & 24 & - & 54 & 81 \\
\hline & & & Sand pool & 2 & 7 & 215 & 147 & 32 \\
\hline & & & Sand pool & 4 & - & 253 & 27 & 07 \\
\hline & Kallady & Coastal & Sand pool & 0 & - & - & 12 & - \\
\hline & & & Sand pool & 3 & - & - & 19 & 3 \\
\hline & & & Lagoon margin & 22 & - & 68 & - & - \\
\hline & & & Lagoon margin & 30 & - & 112 & - & - \\
\hline Puttalam & Thonikkal & Inland & Quarry & 0 & - & 67 & 114 & - \\
\hline \multirow[t]{3}{*}{ Ampara } & Periakalappu & Coastal & Sand pool & 18 & - & 12 & - & - \\
\hline & & & Sand pool & 30 & - & 5 & - & - \\
\hline & Dheegavavi & Inland & Pond & 0 & - & 24 & 93 & 49 \\
\hline \multirow[t]{5}{*}{ Trincomalee } & Muthur & Coastal & Sand pool & 0 & 31 & 18 & 25 & - \\
\hline & & & Sand pool & 2 & - & 41 & 06 & - \\
\hline & Muthur & Coastal & Well & 0 & - & 55 & 87 & - \\
\hline & & Coastal & Sand pool & 2 & - & 12 & 27 & - \\
\hline & Palaiyutru & Inland & Irrigation canal & 0 & 7 & 26 & 103 & 26 \\
\hline
\end{tabular}




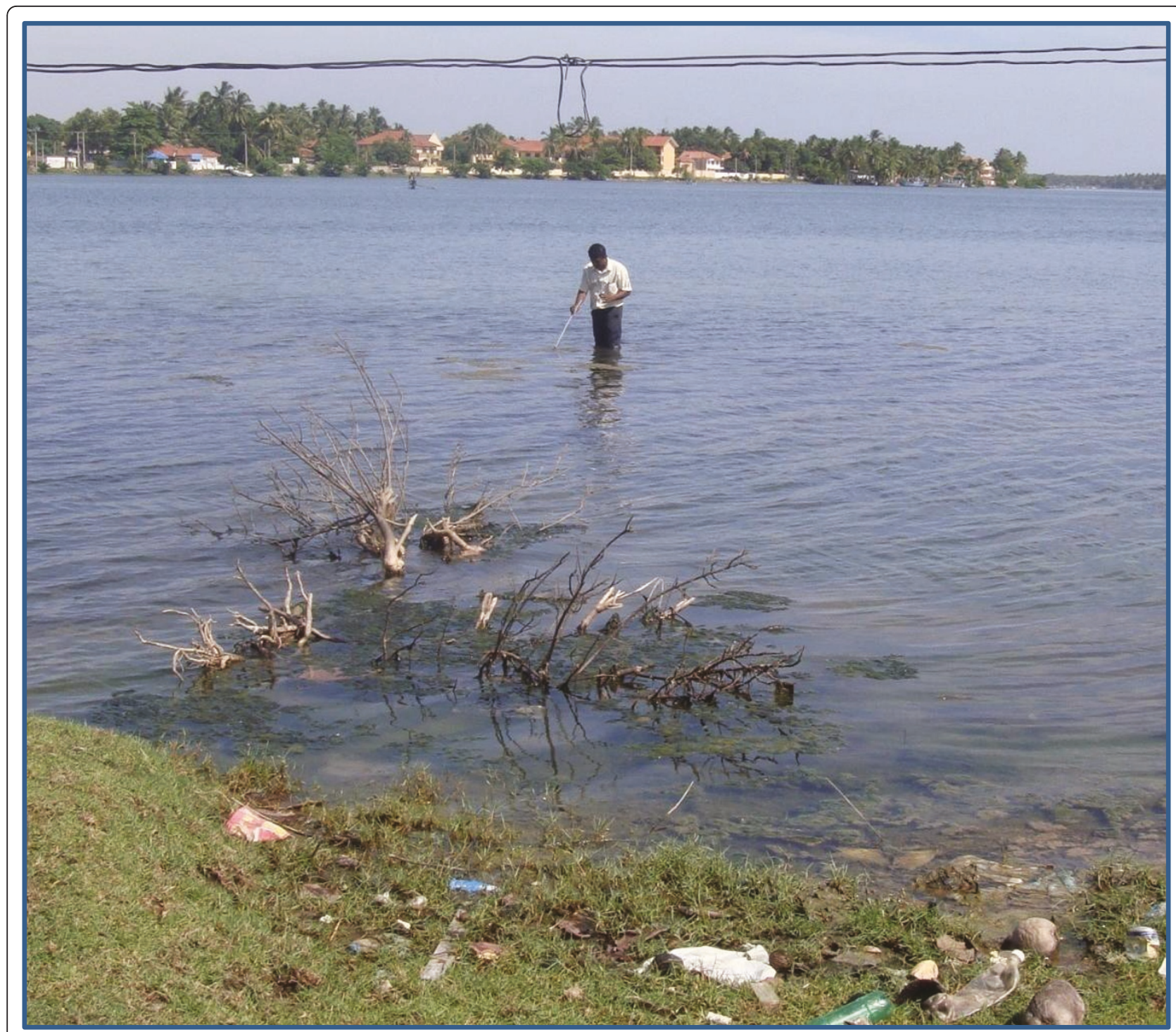

Figure 2 Photograph of the Kallady lagoon site (30 ppt salinity) where An. subpictus species B/An. sundaicus larvae were collected in association with marine algae $>15 \mathrm{~m}$ into the lagoon.

inland. This report is also the first to show that $A n$. subpictus $\mathrm{B} / \mathrm{An}$. sundaicus is able to breed in the shallow, open waters of a lagoon, the Kallady lagoon, in Sri Lanka. The Northern, Eastern and Northwestern provinces of Sri Lanka in particular have many lagoons, with similar characteristics to the Kallady lagoon, as well as other types of highly brackish water bodies [23] that offer potential breeding sites for An. subpictus $\mathrm{B} /$ An. sundaicus.

The use of morphological characteristics of eggs and larvae alone to differentiate members of the An. subpictus complex can have drawbacks [15]. DNA sequence-based tests suitable for field use are not available for differentiating An. subpictus sibling species and the reported cytogenetic differences between them are not useful for field studies [8]. Further studies to correlate the morphological, cytogenetic and molecular characteristics of members of the Subpictus Complex are clearly needed. However, salinity tolerance tests have been reported to be useful in separating morphologically similar members of anopheline species complexes. Sweeney [24] reported that exposure of the first instar larvae to sea water for $1 \mathrm{~h}$ would help separating An. farauti No. 1 (An. farauti s.s.) from other members of the Farauti Complex. Similarly, a salinity tolerance test, using 3 parts sea water having $3.2 \% \mathrm{NaCl}$ and 1 part fresh water which is expected to be 24 ppt salinity, has been reported to separate species A and B of the Subpictus Complex in India [14]. The present study suggests that larval tolerance to 15 ppt salinity may provide a simple and inexpensive method for use in 


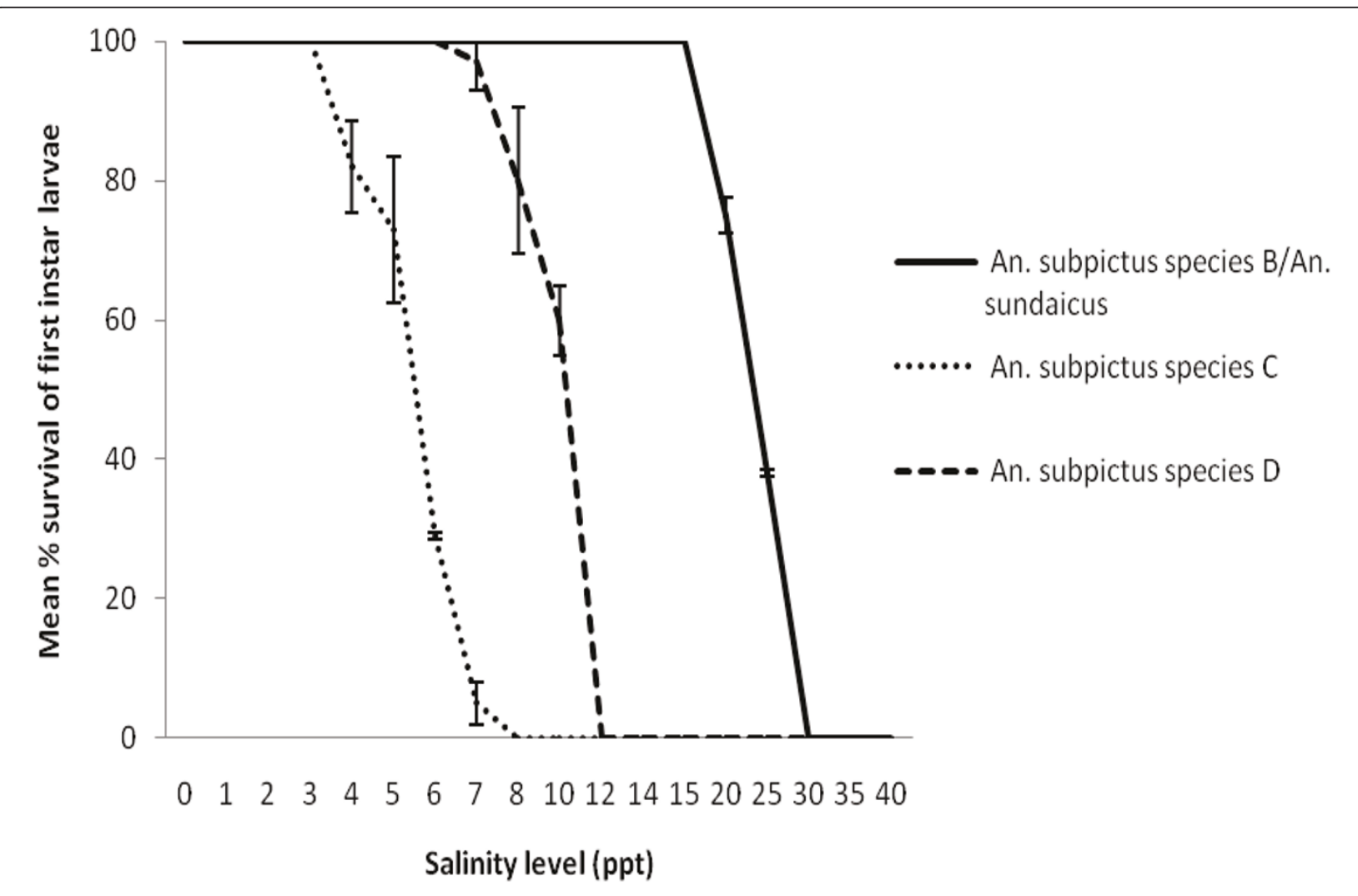

Figure 3 Mean percentage survival to adulthood of first instar larvae of An. subpictus B/ An. sundaicus, and An. subpictus C and D at different levels of salinity.

field studies to separate mosquitoes with morphological characteristics of An. subpictus $\mathrm{B} / A n$. sundaicus from others with characteristics of An. subpictus species $\mathrm{C}$ and $\mathrm{D}$ in Sri Lanka. Additional investigations are needed to determine the applicability of the proposed test to sibling species A in Sri Lanka, which is generally regarded as a freshwater breeding mosquito species.

The incidence of malaria in Sri Lanka, including in its Eastern and Northwestern provinces, has markedly decreased in the past decade due in part to an effective vector control program $[1,2]$. It has previously been proposed that rising sea levels due to global warming may increase the breeding of salinity-tolerant malaria vectors in coastal areas [25]. Taken together with the present findings, it may therefore be prudent to carefully monitor the breeding of malaria vectors in coastal brackish waters, and apply appropriate control measures where necessary, in order to maintain good malaria control in Sri Lanka. Similar considerations also apply to many Southeast Asian countries. Water management involving tidal flushing of breeding sites and source reduction using salinization are sometimes adopted to eliminate mosquito breeding $[26,27]$. However this approach in Sri Lanka and elsewhere in Southeast Asia needs careful consideration when vectors such as $A n$. subpictus $\mathrm{B} / A n$. sundaicus, that are able to breed in brackish and saline waters, are present.

\section{Conclusions}

The four sibling species A, B, C and D of An. subpictus identified through morphological characteristics attributed to Indian members of the An. subpictus complex, are present in Sri Lanka. An. subpictus A, C and D are generally predominant in inland areas, while An. subpictus $\mathrm{B} /$ $A n$. sundaicus tends to be more prevalent in coastal localities. An. subpictus B/An. sundaicus in Sri Lanka is also able to breed in fresh to highly brackish waters including the Kallady lagoon with a salinity of $30 \mathrm{ppt}$. Brackish waters of similar high salt concentration are present in many coastal areas of Sri Lanka and Southeast Asian countries. This heightens the risk of malaria transmission in coastal areas which may be further exacerbated by rising sea levels increasing ground water salinization. Systematic monitoring of larval breeding habitats along the coastal belts of Sri Lanka and many Southeast Asian countries and the development of appropriate vector control measures are therefore needed. Based also on laboratory studies on salinity tolerance of larvae it is proposed that tolerance to 15 ppt salinity may 


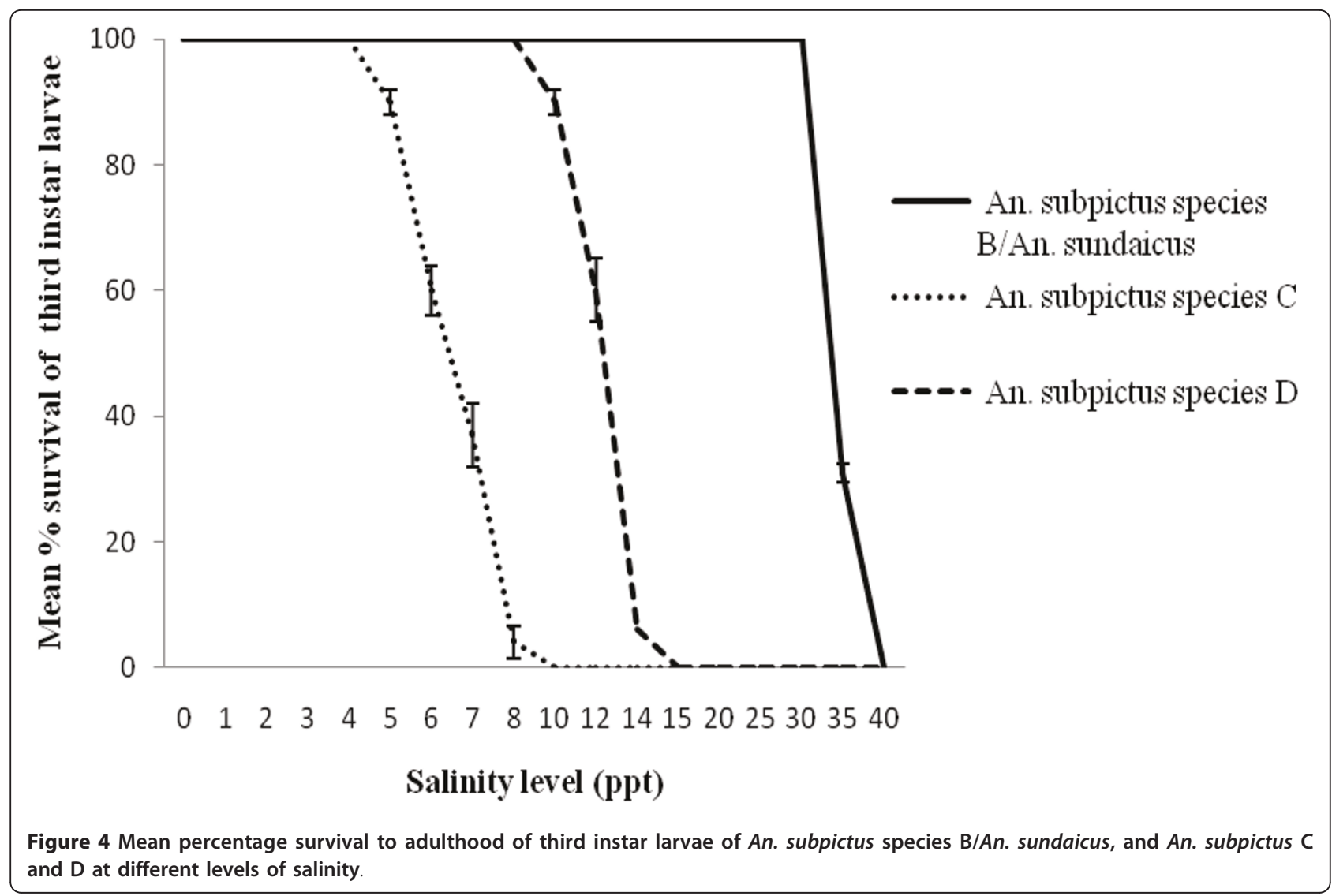

constitute a simple method for differentiating An. subpictus $\mathrm{B} / \mathrm{An}$. sundaicus larvae from those of An. subpictus species $\mathrm{C}$ and $\mathrm{D}$ in field studies.

\section{Methods}

\section{Mosquito collection and identification of sibling species} of the Subpictus Complex

Adult anopheline mosquitoes were collected monthly in the two-year period July 2008 to June 2010 from five sites viz. Oluvil (coastal locality $\sim 2 \mathrm{~km}$ from the coast) Chenkalady (inland locality $\sim 5 \mathrm{~km}$ from the coast) and Muthur (inland locality $\sim 3 \mathrm{~km}$ from the coast; coastal locality $\sim 1 \mathrm{~km}$ from the coast) in the districts of Ampara, Batticaloa and Trincomalee respectively of the Eastern province and from Thonikkal (inland locality $\sim 10 \mathrm{~km}$ from the coast) in the Puttalam district of the Northwestern province, all of which are located in the dry zone of Sri Lanka [Figure 1]. Collection sites located $<2.5 \mathrm{~km}$ from the coast are termed coastal sites. Cattle baited hut $(\mathrm{CBHC})$ and cattle baited net (CBNC) collection techniques were used to collect adult female mosquitoes.

Larvae were also collected between February 2009 and June 2010 from coastal and inland locations in four administrative districts: Periakalappu (coastal locality $\sim 1 \mathrm{~km}$ from the coast) and Dheegavavi (inland locality $\sim 26 \mathrm{~km}$ from the coast) in the Ampara district, Thonikkal (inland locality $\sim 10 \mathrm{~km}$ from the coast) in the Puttalam district, Chenkalady (inland locality $\sim 5 \mathrm{~km}$ from the coast) and Kallady lagoon in the Batticaloa district and Muthur (coastal locality $\sim 1 \mathrm{~km}$ from the coast) and Palaiyutru (inland locality $\sim 2.5 \mathrm{~km}$ from the coast) in the Trincomalee district [Figure 1] using an $8 \mathrm{~cm}$ diameter and $240 \mathrm{ml}$ capacity dipper as previously described [2]. Salinity of water samples was measured using a salinometer (Atago, Japan). The $\mathrm{pH}$ (Hanna Instruments, HI 98128, Rumania) and dissolved oxygen (Hanna Instruments, HI 8043, Rumania) were also measured in the collected water samples.

The collected adults and larvae were brought to the Zoology laboratory of the Eastern University and identified as An. subpictus s.l. using published keys [28-30]. Morphologically identified blood-fed females were maintained individually and single female $F_{1}$ progenies were raised as described previously [31]. The sibling species status of females laying eggs was determined through the reported number of ridges in the floats of egg i.e. species A, 31-36; An. subpictus B/An sundaicus, 16-20; species C, 25-29 and species D, 21-24 [7]. Five to ten eggs from each female were placed on a clean microscopic slide and the number of ridges on floats counted under a light 
microscope (x4, Olympus). Larvae emerging from identified isofemale progenies were used for salinity tolerance experiments.

\section{Salinity tolerance tests on larvae of An. subpictus sibling species}

An. subpictus B/An. sundaicus, An. subpictus $\mathrm{C}$ and An. subpictus D larvae were pooled separately. There were insufficient numbers of $A n$. subpictus species A females in field collections to generate the required numbers of larvae for salinity tolerance tests. First and early third instar larvae of each sibling species were exposed to different salinity levels viz. $0,1,2,3,4,5,6,7,8,10,12$, $14,15,20,25,30,35,40$ ppt ( parts per thousand of salt). Required salinities were obtained either by adding tap water ( 0 ppt salinity) or $\mathrm{NaCl}$ to seawater (36 ppt salinity) $[14,32]$. Salinty was measured using a refractor salinometer (Atago, Japan). Twenty larvae in $150 \mathrm{ml}$ capacity plastic containers containing $100 \mathrm{ml}$ of water of specific salinity were maintained at room temperature $\left(28 \pm 2^{\circ} \mathrm{C}\right)$ until their emergence as adults. Three replicates with 20 larvae each were run in parallel at each salinity level. Plastic lids were used to cover the containers to minimise evaporation. Test media were changed every alternate day. Larvae were fed twice daily with locally available powered fish meal. The number of adults emerging was determined and the results recorded as the mean percentage survival of larvae to reach adulthood at each salinity level \pm standard error of the mean.

\section{Acknowledgements}

The authors thank Ms Rena Verginate Edward for Figure 1 and Dr. M. Vinobaba (Department of Zoology, Eastern University of Sri Lanka) for logistical support. This study was supported by the National Science Foundation of Sri Lanka grant SIDA/BT/2006/03.

\section{Author details}

'Department of Zoology, Faculty of Science, University of Jaffna, Jaffna, Sri Lanka. ${ }^{2}$ Institute of Health Sciences, Universiti Brunei Darussalam, Gadong, Brunei Darussalam

\section{Authors' contributions}

SNS and RR conceived the study. PJJ performed field collections. PJJ and SNS carried out laboratory studies. SNS and RR wrote the manuscript. All authors read and approved the final manuscript.

\section{Competing interests}

The authors declare that they have no competing interests.

Received: 18 May 2011 Accepted: 24 June 2011 Published: 24 June 2011

\section{References}

1. Surendran SN, Ramasamy R: The Anopheles culicifacies and An. subpictus complexes in Sri Lanka and their implications for malaria control in the country. Trop Med Health 2010, 38:1-11.

2. Jude PJ, Dharshini S, Vinobaba M, Surendran SN, Ramasamy R: Anopheles culicifaciesbreeding in brackish waters in Sri Lanka and implications for malaria control. Malar J 2010, 9:106.

3. Amerasinghe PH, Amerasinghe FP, Wirtz RA, Indrajith NG, Somapala W, Preira LR, Rathnayake AMC: Malaria transmission by Anopheles subpictus
Grassi in a new irrigation project in Sri Lanka. J Med Entomol 1992, 29:577-581.

4. Ramasamy R, Ramasamy MS, Wijesundera DA, Wijesundera AP, de S, Dewit I, Ranasinghe C, Srikrishnarajah KA, Wickramarantne C: High seasonal malaria transmission rates in the intermediate rainfall zone of Sri Lanka. Ann Trop Med Parasitol 1992, 86:591-600.

5. Amerasinghe $\mathrm{PH}$, Amerasinghe FP, Kondradsen F, Fonseka KT, Wirtz RA: Malaria vectors in a traditional dry zone village in Sri Lanka. Am J Trop Med Hyg 1999, 60:421-429.

6. Chandra G, Bhattacharjee I, Chatterjee S: A review on Anopheles subpictus Grassi - A biological vector. Acta Trop 2010, 115(1-2):142-154.

7. Suguna SG, Rathinam KG, Rajavel AR, Dhanda V: Morphological and chromosomal descriptions of new species in the Anopheles subpictus complex. Med Vet Entomol 1994, 8:88-94.

8. World Health Organisation: Anopheline Species Complexes in South and South-East Asia SEARO Technical Publication No.57. World Health Organisation. Geneve; 2007, 73-76.

9. Thenmozhi V, Rajendran R, Ayanar K, Manavalan R, Tyagi BK: Long-term study of Japanese encephalitis virus infection in Anopheles subpictus in Cuddalore district, Tamil Nadu, South India. Trop Med Int Health 2006, 11(3):288-293

10. Hubálek Z, Halouzka J: West Nile fever - a reemerging mosquito-borne viral disease in Europe. Emerg Infect Dis 1999, 5(2):643-650.

11. Abhayawardana TA, Wijesuria SRE, Dilrukshi RRKC: Anopheles subpictus complex: distribution of sibling species in Sri Lanka. Indian J Malariol 1996, 33:53-60.

12. Abhayawardana TA, Wickramasinghe MB, Amerasinghe FP: Sibling species of Anopheles subpictus and their seasonal abundance in Chilaw area. Proc Sri Lanka Assoc Advan Sci 1999, 55:17.

13. Sinka ME, Bangs MJ, Chareonviriyaphap T, Patil AP, Temperley WH, Gething PW, Elyazar IRF, Kabaria CW, Harbach RE, Hay SI: The dominant Anopheles vectors of human malaria in the Asia-Pacific region: occurrence data, distribution maps and bionomic précis. Parasites \& Vectors 2011, 4:89.

14. Reuban R, Kalyanasundaram M, Suguna G: Salinity tolerance of sibling species in the taxon Anopheles subpictus Grassi, 1899. Indian J Med Res 1984, 80:67-70.

15. Surendran SN, Singh OP, Jude PJ, Ramasamy R: Genetic evidence for malaria vectors of the Anopheles sundaicus complex in Sri Lanka with morphological characteristics attributed to Anopheles subpictus species B. Malar J 2010, 9:343.

16. Surendran SN, Hawkes NJ, Steven A, Hemingway J, Ramasamy R: Molecular studies of Anopheles culicifacies (Diptera: Culicidae) in Sri Lanka: sibling species B and E show sequence identity at multiple loci. Eur J Entomol 103:233-237.

17. Coluzzi M, Sabatini A: Cytogenetic observations on the salt water species, Anopheles merus and Anopheles melas of the Gambiae complex. Parassitologia 1969, 11:177-187.

18. Foley $\mathrm{DH}$, Bryan $\mathrm{JH}$ : Shared salinity tolerance invalidates a test for the malaria vector Anopheles farauti s.s. on Guadalcanal, Solomon Islands. Med Vet Entomol 2000, 14:450-452.

19. Sharma SK, Adak T, Haq S, Kar I: Observations on the relationship of salinity with the breeding habitats of Anopheles sundaicus (Diptera: Culicidae) at Car Nicobar Islands, India. Mosquito-Borne Diseases Bulletin 1999, 16:33-36

20. Collins RT, Jung RK, Anoez H, Sutrisno RH, Putut D: A study of the coastal malaria vectors Anopheles sundaicus (Rodenwaldt) and Anopheles subpictus (Grassi) in South Sulawesi, Sulawesi, Indonesia. WHO/MAL/79.913.

21. Panicker KN, Geetha BM, Bheema RUS, Wiswam K, Suryanarayana MU: Anopheles subpictus: vector of malaria in coastal villages of southeast India. Curr Sci 1981, 50:694-695.

22. Sahu SS: Comparative susceptibility of Anopheles subpictus from fresh and brackish water areas to Plasmodium falciparum infection. Acta Trop 1998, 70:1-7.

23. Steele P, Konradsen F, Imbulana KAUS: Irrigation, health, and the environment: A literature review with examples from Sri Lanka Colombo, Sri Lanka: IIMI. V, 25p; 1997, (Discussion Paper No. 42).

24. Sweeney AW: Larval salinity tolerances of the sibling species of Anopheles farauti. J Am Mosq Cont Assoc 1987, 3:589-592.

25. Ramasamy R, Surendran SN: Possible impact of a rise in sea levels on vector-borne infectious diseases. BMC Infect Dis 2011, 11:18. 
26. Daggy RH: The biology and seasonal cycle of Anopheles farauti on espiritu Santo New Hebrides. Ann Entomol Soc Am 1945, 38:3-13.

27. Foley DH, Bryan JH: Oviposition preference for freshwater in the coastal malaria vector, Anopheles farauti. J Am Mosa Cont Assoc 1999, 15:291-294.

28. Christophers SR: The Fauna of British India, including Ceylon and Burma. Diptera 4. Family Culicidae. Tribe Anopheline Taylor \& Francis, London; 1933.

29. Amerasinghe FP: A guide to the identification of the anopheline mosquitoes (Diptera: Culicidae) of Sri Lanka-I Adult females. Ceylon J Sci (Bio Sci) 1990, 21:1-16.

30. Amerasinghe FP: A guide to the identification of the anopheline mosquitoes (Diptera: Culicidae) of Sri Lanka-II Larvae. Ceylon J Sci (Bio Sci) 1992, 22:1-13

31. Surendran SN, Ramasamy MS, De Silva BGDNK, Ramasamy R: Anopheles culicifacies sibling species $B$ and $E$ in Sri Lanka differ in longevity and in their susceptibility to malaria parasite infection and common insecticides. Med Vet Entomol 2006, 20:153-156.

32. Mosha FW, Subra R: Salinity and breeding of Culex quinquefasciatus Say, Anopheles funestus Giles and Anopheles gambiae Giles sensu stricto (Diptera: Culicidae) on the Kenya Coast. Cah ORSTOM sér Ent méd et Parasitol 1983, XXI: 135-138.

doi:10.1186/1756-3305-4-117

Cite this article as: Surendran et al:: Variations in salinity tolerance of malaria vectors of the Anopheles subpictus complex in Sri Lanka and the implications for malaria transmission. Parasites \& Vectors 2011 4:117.

\section{Submit your next manuscript to BioMed Central and take full advantage of:}

- Convenient online submission

- Thorough peer review

- No space constraints or color figure charges

- Immediate publication on acceptance

- Inclusion in PubMed, CAS, Scopus and Google Scholar

- Research which is freely available for redistribution

Submit your manuscript at www.biomedcentral.com/submit 